\title{
Em busca do patrimônio intangível: dificuldades, estratégias e caminhos para a reconstrução do patrimônio imaterial das fazendas históricas paulistas
}

Aiming for the intangible heritage: difficulties, strategies and solutions to rebuild the immaterial heritage from the historical farms from São Paulo

\author{
Olga Rodrigues de Moraes von Simson \\ Socióloga e pesquisadora do Centro de Memória-Unicamp (CMU) \\ E-mail:simson@superig.com.br
}

\section{ReSUMo}

Depois de reconstruir o processo de constituição da noção de patrimônio intangível ou imaterial em nosso país, mostrando os principais estudiosos que buscaram sua construção, registro e a inserção dessa preocupação na Constituição de 1988, o texto busca mostrar como o projeto Fazendas Históricas Paulistas vem trabalhando essa questão, ao tentar reconstruir o patrimônio imaterial de cada fazenda, através de depoimentos orais colhidos com proprietários e/ou trabalhadores que vivem há muito tempo na propriedade.

Palavras-chave: Fazendas históricas; Patrimônio imaterial ou intangível; História oral

\section{ABSTRACT}

After the effort to recreate the concept of an intangible or immaterial heritage in Brasil, highlighting the most famous experts that aimed for it construction, register and insertion in the 1988's Constitution, this present studying aims to report how the project "Fazendas Históricas Paulistas" have been working with this subject while tries to rebuild the immaterial heritage of each farm through oral speeches of the farm's owners and worker whom have spend a large time on those properties.

Keywords: Historical farms; Immaterial or intangible heritage; Oral history 
A preocupação com o conhecimento e registro do patrimônio imaterial ou intangível [1] em nosso país já é bem antiga. Mário de Andrade na famosa expedição que realizou ao Nordeste brasileiro, nos anos 30 do século passado, foi pioneiro na busca, registro e incentivo às criações populares no âmbito dos ritos, da música, da dança, dos hábitos, das crenças e do folclore, constituintes de um rico patrimônio imaterial, até então desconhecido e pouco valorizado. Seu livro O Turista Aprendiz inaugura a discussão sobre o tema da cultura imaterial em nosso país, ao registrar os contatos que manteve com os mestres da cultura popular nordestina, no grande esforço de conhecer os modos de fazer nos ritos, na música, na dança, na culinária, nos ofícios e nos costumes, todos eles aspectos constituintes dessa riquíssima diversidade do nosso patrimônio intangível. Mário de Andrade foi precursor de uma atitude que considera que não são os objetos os elementos mais importantes na cadeia do patrimônio, mas sim as maneiras de fazer, isto é, o processo envolvido na sua produção.

A atuação desse intelectual junto ao Departamento de Cultura de São Paulo foi inovadora, pois desenvolveu uma proposta avançada de recolha do patrimônio intangível, ao já utilizar nos anos 30 e 40 do século passado, as então novíssimas tecnologias de registro sonoro e de filmagem, visando a captação e a salvaguarda [2] de documentação original sobre as mais diversas formas de manifestação cultural das classes populares do nosso país.

Outros intelectuais o sucederam nessas preocupações como Aluísio Magalhães que criou o CNRC (Centro Nacional de Referências Culturais) no início dos anos 80 e introduziu o debate sobre processos de homogeneização cultural, de assimilação de práticas culturais externas e sobre a influência das transformações provenientes de inovações tecnológicas em diversos aspectos da cultura nacional. Uma das grandes conquistas de Magalhães foi a introdução de um novo conceito de patrimônio cultural que abrangia também "o gesto, o hábito, a maneira de ser da nossa comunidade",[3] conseguindo dessa forma estender a proteção legal ao patrimônio intangível ou imaterial, até então não reconhecido e podendo abranger assim aspectos das culturas populares e dos cultos afro-brasileiros.

Luís da Câmara Cascudo realizou trabalho hercúleo cobrindo du-
1- Intangível é o termo cunhado pelos ingleses (intangible heritage) para falar do patrimônio imaterial, buscando distinguir essa herança imaterial daquelas que já estavam contidas nas convenções da Unesco, sob a forma de patrimônios materiais, sejam eles arquitetônicos ou naturais.

2 - Salvaguarda é o termo utilizado, quando tratamos do patrimônio intangivel ou imaterial, para substituir preservação, que poderia sugerir a idéia de museificação, inapropriada para manifestações tão dinâmicas $e$ mutáveis, como as da cultura.

Salvaguardar significa procurar garantir a manutenção dos meios que possibilitam a produção e a manifestação dos bens imateriais

3- Magalhães, $A$. 1985, p.6 
4 - História oral é a metodologia qualitativa que se vale da memória de informantes selecionados para reconstituir oralmente e registraratravés de áudio-gravação ou filmagem, aspectos do passado não contidos em outros suportes. Ela apresenta várias técnicas como: História de Vida, Depoimento Oral, Relato Oral ou Entrevista, que são utilizadas de acordo com os objetivos da pesquisa que se pretende realizar. rante décadas a diversidade cultural nordestina. Também a Fundação Joaquim Nabuco, através dos pesquisadores de seu Centro de Estudos Folclóricos, tem tido papel relevante nas pesquisas que mapearam e registraram a riqueza cultural de Pernambuco. Assim, aos poucos, foi se constituindo, com o apoio dos antropólogos que enfatizavam a importância da nossa diversidade cultural, uma consciência difusa o que resultou na inclusão na Constituição de 1988 de referências ao patrimônio cultural brasileiro, entendido como "os bens de natureza material e imaterial, tomados individualmente ou em conjunto, portadores de referência à identidade, à ação, à memória dos diferentes grupos”. ( Brasil. Constituição de 1988)

Em 2000 o país realizou um importante avanço nessa questão ao aprovar o Decreto 3.551 que criou o Registro de Bens Culturais de Natureza Imaterial que constituem o patrimônio cultural brasileiro e se antecipou à Convenção de Salvaguarda do Patrimônio Cultural Imaterial realizada em Paris em 2003.

Existem muitas definições de patrimônio imaterial ou intangível, mas a que mais se adequa ao tipo de trabalho que realizamos é aquela que salienta que ele é fruto da vida em sociedade. Assim, para que ele exista e possa ser captado, é necessária a presença de uma comunidade com intensa vida social capaz de gerar manifestações culturais como ritos, festas, quermesses, novenas, crenças, romarias que produzam músicas, danças, poesias, rezas, criações nas artes plásticas, no artesanato e no folclore local.

A pesquisa em fazendas históricas paulistas tem se preocupado em captar esse patrimônio imaterial, ainda existente no meio rural paulista e quando, por motivos vários, sua força no presente, se mostra débil ou inexistente, temos trabalhado com a memória dos atores sociais que viveram na fazenda, no auge de sua vida econômica e social para reconstruirmos e registrarmos a riqueza que esse patrimônio imaterial teve no passado.

Com o auxílio do método biográfico ou da história oral, [4] entrevistamos o proprietário e também o funcionário que há mais tempo vive na propriedade, com o objetivo de recuperarmos a memória da vida social passada e da riqueza patrimonial que ela produziu, através de enfoques provenientes de duas classes sociais diversas. 
Também nos preocupamos em saber se existem iniciativas, por parte do proprietário ou do poder público municipal, visando a divulgação do patrimônio intangível produzido localmente, tanto para crianças e adolescentes que visitam a propriedade histórica, como para grupos de adultos e idosos que a procuram, no intuito de rever aspectos do passado que foram importantes para familiares, amigos ou vizinhos de mais idade.

Essa recuperação do patrimônio intangível ainda presente nas fazendas históricas e que constitui a alma desses espaços arquitetônicos que datam dos séculos XVIII ou XIX não é nem rápida e muito menos simples. Em primeiro lugar, faz-se necessário construir uma relação de confiança, tanto com o proprietário, como com o funcionário que há mais tempo reside na fazenda, pois nos interessa enxergar esse passado, definidor das marcas culturais formadoras do patrimônio imaterial, através do olhar de pelo menos duas classes sociais, ainda ali presentes e que foram as construtoras da riqueza econômica, social e cultural paulistas.

\section{DESCRIÇÃO DOS TRABALHOS REALIZADOS EM CAMPO}

Nas visitas técnicas que realizamos às propriedades históricas, fazemos uma rápida passagem pelo patrimônio arquitetônico preservado e escolhemos um local mais calmo e isolado solicitando então ao proprietário que nos indique o funcionário mais antigo, ainda vivendo no local, para colhermos sua história de vida na fazenda. Enquanto nossos colegas, que se preocupam com a localização e registro do patrimônio tangível, observando, medindo, fotografando e filmando a riqueza material ainda presente na propriedade, nós mergulhamos no seu passado recente para, junto com o trabalhador rural local, reconstruirmos como se deu a vida social na propriedade e quais foram os tempos importantes para festejar a boa colheita, para agradecer benesses aos santos padroeiros ou orar fervorosamente na pequena capela, quando secas prolongadas ou pestes ameaçadoras, colocavam em risco esse viver simples e ligado a terra.

A primeira parte dessa coleta de dados é constituída de uma explanação ao trabalhador rural sobre a importância da reconstrução dos aspectos imateriais do passado recente, que não estão mais presentes de maneira concreta, pelo desmonte da comunidade de trabalho que dava vida à propriedade cafeeira e da qual ele muitas vezes é o único remanescente. 
Explicamos a ele que é na riqueza da sua memória que se mantêm presentes e ainda vivos os aspectos desse viver interiorano e que contamos com sua paciência e participação para que, através dos fragmentos de memória que ele consiga reconstruir, possamos ter uma idéia, ainda que aproximada, de como foi o viver social local no auge da produção cafeeira.

Quando nossos colegas, encarregados da localização e registro do patrimônio material móvel, localizaram fotos antigas que focalizam as atividades de caráter mais comunitário como, por exemplo, o beneficiamento do café, as festas do fim da colheita, as novenas e quermesses, nós as utilizamos como detonadoras do processo de rememoração do nosso entrevistado, conseguindo assim construir indagações mais adequadas à realidade local e datar melhor as várias fases por que passou a propriedade estudada.

Dessa maneira, geralmente conseguimos colher um depoimento que alterna rememorações prazerosas do passado, com constatações sofridas da pobreza cultural da vida social contemporânea, nas propriedades históricas visitadas e a manifestação do prazer, que esse trabalhador diz encontrar, ao relatar para crianças e adolescentes, como era o viver nos espaços que eles hoje vêm conhecer. Os trabalhadores entrevistados muitas vezes também falam da realização que encontram ao liderar os passeios eqüestres e as cavalgadas, realizados com os hóspedes pelos caminhos e trilhas da fazenda, que ele tão bem conhece.

Após uma boa refeição, em que degustamos as delícias locais e nos preocupamos em reconstruir com a proprietária, os modos de fazer, dos pratos típicos da fazenda e da doçaria regional, ágape sempre seguido de um delicioso cafezinho, coado a partir dos grãos, cultivados, torrados e moídos na propriedade, chega o momento de convidarmos o fazendeiro ou a proprietária (no caso de uma viúva responsável pela fazenda), para nos sentarmos nos amplos terraços, que via de regra circundam a casa sede, para uma longa conversa. É nesse papo, de caráter mais informal, que procuramos reconstruir a memória familiar, invariavelmente entrelaçada a história da propriedade agrícola, porque são elas que nos fornecem as chaves para o entendimento do patrimônio imaterial, tanto o de origem popular, como também aquele produzido pelo grupo familiar. Este se 
encontra muitas vezes registrado em álbuns fotográficos ou em cadernos de poesia ou de cantigas, as manifestações culturais informais que animavam as noites na fazenda, ainda antes das vitrolas e da televisão.

Esses depoimentos,(construídos com o apoio de um roteiro orientador, para que se tornem documentos comparáveis em nossas posteriores análises de caráter histórico-sociológico) são gravados digitalmente e depois transcritos com o auxílio dos técnicos do LAHO (Laboratório de História Oral) do Centro de Memória-Unicamp (CMU). Eles se transformam assim, em documentos escritos, que permitirão a realização de análises temáticas e de conteúdo, ambas preciosas para a construção de um conhecimento novo sobre tais espaços de caráter privado, que eram inacessíveis aos pesquisadores, antes do convênio, realizado entre as quatro universidades públicas (Unicamp, USP, Unesp e UFSCar) e a Associação das Fazendas Históricas Paulistas e que deu origem à presente pesquisa.

Dessa maneira nosso arquivo já contem cerca de quarenta depoimentos orais cobrindo a primeira fase do projeto e se ampliará, nessa segunda fase, quando pesquisaremos propriedades da zona da Mogiana, ao Nordeste do Estado de São Paulo, já na divisa com Minas Gerais, além de algumas fazendas históricas do Vale do Paraíba.

Uma outra preocupação do nosso grupo, que pesquisa o patrimônio imaterial, é a de saber como os aspectos do patrimônio intangível se fazem presentes nas ações de turismo cultural e de educação patrimonial, promovidas pelas fazendas históricas pesquisadas.

\section{TIPOLOGIA DAS FAZENDAS PESQUISADAS}

Ao longo da pesquisa conseguimos construir uma tipologia das fazendas integrantes da pesquisa que podem ser agrupadas em três grandes tipos:

A) Aquelas que possuem um patrimônio material e imaterial significativo, em fase de pesquisa e registro. Tais propriedades se encontram em fase de organização para receber turistas e escolares, mas ainda não iniciaram a divulgação da sua riqueza cultural e desejam uma assessoria especializada da universidade, através da presente pesquisa, para realizar essa 
tarefa com competência e qualidade.

$B$ ) Aquelas que, tendo seu patrimônio cultural (material e imaterial) pesquisado e registrado, já se organizaram e iniciaram timidamente processos de divulgação atraindo localmente grupos interessados em conhecer a propriedade e desfrutar de um turismo tipo 'day use' explorando seus espaços e vivenciando algumas atividades culturais. Gostariam de receber orientação da equipe de pesquisadores para melhorarem o acolhimento aos visitantes e proporcionarem a eles vivências culturais mais significativas. Algumas dessas propriedades já recebem turistas (principalmente estrangeiros) que permanecem por todo um fim de semana, acompanhando as atividades realizadas na fazenda, vivendo nos quartos desocupados da casa-sede e se alimentando à mesa com os membros da família proprietária, numa modalidade turística denominada 'turismo de habitação'. Também costumam receber crianças e adolescentes, trazidos pelas escolas dos municípios vizinhos que experimentam uma educação patrimonial orientada por professores locais ou pelo proprietário, que possui formação universitária. Quando os grupos de visitantes são muito numerosos os fazendeiros costumam contratar estudantes universitários da região para realizar, na função de estagiários/monitores, as explicações de caráter histórico dos acervos patrimoniais de caráter material e imaterial. Como exemplo, desse tipo de propriedade, temos a Fazenda Mandaguahy de Jaú, a Fazenda Quilombo de Limeira ou a Chácara do Rosário de Itu.

C) O terceiro tipo de fazenda identificado, reuni as propriedades que investiram capital significativo e adaptaram seus espaços para o recebimento de hóspedes, se transformando em 'hotéis-fazenda'. Elas oferecem hospedagem de alto nível, acompanhada de atividades como trecking, por trilhas especialmente preparadas, cavalgadas diurnas e ao luar ou, até mesmo, expedições de vários dias, a cavalo, para conhecer o interior do estado e outras propriedades da região. Como exemplo, desse tipo de propriedade, temos a Fazenda Capoava em Itu ou a Fazenda Bela Vista, em Dourado.

$\mathrm{Na}$ maioria delas, entretanto, quem realiza o atendimento diferenciado dos hóspedes, agregando às atrações oferecidas um toque de saborosas histórias sobre o passado da fazenda, são os proprietários ou seus familiares (raramente encontramos um funcionário, que já vive há muitos anos na 
propriedade, prestando alguma ajuda), pois fica muito difícil delegar essa tarefa a jovens estagiários de nível universitário, porque além da formação histórica, há de estar presente também um toque especial sobre as especificidades locais.

Portanto, cabe também aos pesquisadores envolvidos na presente pesquisa em fazendas históricas paulistas desenvolver metodologias de recebimento dos hóspedes e turistas, capazes de reunir algumas informações sobre o contexto histórico regional, mas também aspectos socioculturais da propriedade, numa mistura competente que torne a capacitação dos estagiários bastante completa e capaz de transformá-los em membros ativos da vida na propriedade, conhecendo não só os aspectos materiais, mas também as especificidades históricas e culturais da fazenda, captadas via história oral e estrategicamente anexadas aos roteiros turísticoculturais adaptados para crianças, adolescentes e idosos.

Para que esse objetivo seja alcançado é de importância fundamental a pesquisa dos aspectos imateriais do patrimônio cultural local, capazes de fornecer justamente o plus necessário para transformar os jovens monitores em guias especialmente treinados, hábeis ao revelar aos visitantes, não só a riqueza arquitetônica e paisagística dos espaços visitados, mas a alma dessas configurações espaciais que está contida no patrimônio imaterial, construído pela comunidade local durante mais de um século de vida rural.

\section{REFERÊNCIAS BIBLIOGRÁFICAS}

ARANTES, Antonio Augusto. "O patrimonio imaterial e a sustentabilidade de sua salvaguarda”.In Resgate - Revista de Cultura do Centro de MemóriaUnicamp) "Memória e patrimônio: territórios e cenários de lembranças". no.13, 2004, pp 11 a 18

BURKE, Peter. O que é História Cultural? Trad. Sérgio Góes de Paula. $2^{\mathrm{a}}$. ed. rev. e ampl. Rio de Janeiro. Jorge Zahar Ed., 2008

COUCEIRO, Sylvia; BARBOSA, Cibele. "Patrimonio imaterial: debates contemporâneos”. In: Cadernos de Estudos Sociais - Recife; Fundação Joaquim Nabuco, Instituto de Pesquisas Sociais, 1985, vol. 1, pp. 151 a 160 LANG, Alice B. S. Gordo (org.) Desafios da Pesquisa em Ciências Sociais. Textos CERU, Série 2, no. 8, 2001. 
LANG. Alice .B.S.Gordo et al. História Oral e Pesquisa Sociológica. A Experiência do CERU; São Paulo. Humanitas, 2001

MAGALHÃES, Aloísio. A Questão dos Bens Culturais no Brasil.R. Jan. Nova Fronteira; Brasília; Fundação Nacional Pró-Memória, 1985

MONTENEGRO, Antonio T. História Oral e Memória. A Cultura Popular Revisitada. $3^{\text {a }}$. ed. S.Paulo - Contexto, 1994

Leopoldianum. (Revista de Estudos e Comunicações da Universidade Católica de Santos.) Número Especial "Patrimônio cultural imaterial Histórias, contos e lendas”. Ano 35 - jan.-abril 2009, no. 95.

VISCARDI, Claudia M.R. \& DELGADO, Lucila de A. Neves. História Oral. Teoria, Educação e Sociedade. Juiz de Fora, Ed. UFJF, 2006 VON SIMSON, Olga R. de Moraes. "Memória, cultura e poder na sociedade do esquecimento". In: Margens. Revista Interdisciplinar do Núcleo de Pesquisa - CUBT/UFPA Dossiê Memória e Oralidade, pp. 11 a 16 VON SIMSON, Olga R. de Moraes.(org) Os Desafios Contemporâneos da História Oral. Área de Publicações. Centro de Memória-Unicamp, 1997 VON SIMSON, Olga R. de Moraes. "Reflexões de uma socióloga sobre o uso do método biográfico". In: MEIHY, José C. Sebe Bom (org.) Reintroduzindo a História Oral no Brasil. S. Paulo, Xamã, 1996, pp, 83 a 91 